\title{
A Human 88-kD Membrane Glycoprotein (CD36) Functions In Vitro as a Receptor for a Cytoadherence Ligand on Plasmodium falciparum-infected Erythrocytes
}

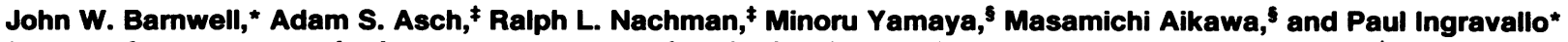

${ }^{*}$ New York University Medical Center, Department of Medical and Molecular Parasitology, New York 10010; ${ }^{\ddagger}$ Cornell University

Medical College, Department of Hematology-Oncology, New York 10021; and ${ }^{\S}$ Case Western University,

Institute of Pathology, Cleveland, Ohio 44106

\begin{abstract}
Plasmodium falciparum-infected erythrocytes (IE) specifcally adhere to vascular endothelium in vivo and to human endothelial cells, some human melanoma cell lines, and human monocytes in vitro. The tissue cell receptor for a ligand on the surface of the infected erythrocytes is an $M_{r} 88,000$ glycoprotein (GP88) recognized by the MAb OKM5, which also blocks cytoadherence of IE. Isolated, affinity-purified GP88 (CD36) competitively blocks cytoadherence and when absorbed to plastic surfaces, specifically binds $\boldsymbol{P}$. falciparum IE. Additionally, monoclonal and polyclonal antibodies to GP88 block cytoadherence to both target cells and immobilized GP88. Binding to GP88 by IE is unaffected by the absence of calcium or the absence of thrombospondin, a putative mediator for cytoadherence of $P$. falciparum IE. Thus, GP88 (CD36), which has been demonstrated to be the same as platelet glycoprotein $I V$, interacts directly with $P$. falciparum IE, presumably via a parasite-induced ligand exposed on the surface of the infected erythrocytes. CD36 is shown to be present on brain endothelium in both individuals without malaria and individuals with cerebral malaria. This would suggest that factors other than just cerebral sequestration of IE play an initiating role in the genesis of cerebral malaria.
\end{abstract}

\section{Introduction}

The adherence of trophozoite-infected erythrocytes to vascular endothelium plays an important role in the biology of Plasmodium falciparum malaria. Erythrocytes infected with ringstage (an early developmental form) parasites circulate freely through the circulatory vasculature. However, as the intraerythrocytic parasites mature the trophozoite-infected erythrocytes disappear from the peripheral circulation and become sequestered in postcapillary venules by adhering to the endothelium $(1,2)$. This cytoadherence of infected erythrocytes (IE) ${ }^{1}$ may have two consequences in the pathogenesis of this

Address reprint requests to Dr. John W. Barnwell, Department of Medical and Molecular Parasitology, New York University Medical School, 341 E. 25th St., New York, NY 10010.

Received for publication 23 March 1989.

1. Abbreviations used in this paper: IE, infected erythrocytes; FVO, Vietnam Oaknoll; MC, Malayan camp; NETT, $0.15 \mathrm{M} \mathrm{NaCl}, 5 \mathrm{mM}$ EDTA, $50 \mathrm{mM}$ Tris, 0.5\% Triton X-100, pH 7.2; SL, Santa Lucia; TSP, thrombospondin.

J. Clin. Invest.

(c) The American Society for Clinical Investigation, Inc. 0021-9738/89/09/0765/08 $\$ 2.00$

Volume 84, September 1989, 765-772 host-parasite relationship. First, by preventing the IE from freely circulating, the parasites promote their survival by avoiding passage through an immunologically active spleen (3, 4). Secondly, the sequestration of IE in vessels of the brain whereby blood flow could be occluded has been thought to be a major factor in the genesis of cerebral malaria (5-7), a sometimes severe, frequently lethal syndrome of $P$. falciparum infections. Study of the host and parasite components involved in the cytoadherence of $P$. falciparum infected erythrocytes may provide mechanisms that could disrupt this interaction and thus inhibit parasite development and moderate the severity of the disease.

In vitro $P$. falciparum IE specifically attach to monolayers of human endothelial cells $(8)$, monocytes $(9,10)$, and some human melanoma cell lines $(11,12)$. In vivo and in vitro, the adherence of IE mediated by junction formation between an area localized over electron dense protrusions (knobs) (13) in the infected erythrocyte membrane and the endothelial cell membrane $(8,14)$. It has been previously shown that an MAb, OKM5 (10), inhibits the in vitro cytoadherence of $P$. falciparum IE to these specific human target cells. OKM5 is reactive with endothelial cells, C-32 human melanoma cells, monocytes, and platelets $(10,15)$ and identifies an $88-\mathrm{kD}$ glycoprotein $(C D 36)$ in the membranes of these cells $(10,15)$. Thus, this glycoprotein appeared to play a role in the cytoadherence of $P$. falciparum IE. Alternatively, thrombospondin (TSP), a soluble, multifunctional adhesive glycoprotein involved in numerous cell-cell and cell-substrate interactions (16) has been reported to mediate the cytoadherence of $P$. falciparum IE (17) when it was shown that $P$. falciparum IE adhered to immobilized TSP. We have recently shown that TSP binds to the $88-\mathrm{kD}$ membrane glycoprotein and that this interaction is inhibited by MAb OKM5 (18).

These observations suggested that cytoadherence possibly involves an interaction between a membrane receptor for TSP (the $88-\mathrm{kD}$ glycoprotein), TSP, and a putative parasite ligand on the infected erythrocyte membrane $(19,20)$. We have isolated the 88-kD membrane glycoprotein (GP88) from C32 melanoma cells and platelets by affinity chromotography and investigated the interactions of IE with this glycoprotein and TSP. Here we report that purified GP88 competitively inhibits cytoadherence and when immobilized on plastic specifically binds $P$. falciparum IE. Furthermore, our results indicate that $P$. falciparum IE interact with C32 melanoma cells and purified GP88 independently of TSP.

\section{Methods}

Parasites. The P. falciparum strains, FCR3, Malayan Camp (MC), Santa Lucia (SL), and Vietnam Oaknoll (FVO), used in this study were adapted to growth in nonsplenectomized Aotus monkeys $(21,22)$. Ring-stage parasites were collected from infected animals at high para- 
sitemia (10-30\%) and cryopreserved in liquid nitrogen by the American Red Cross high glycerol-slow freeze method of erythrocyte freezing $(23,24)$. The FCR3 and FVO strains of $P$. falciparum were also cultured in vitro in human $0^{+}$erythrocytes and cryopreserved at the ring stage at $10-15 \%$ parasitemias. The above isolates were knob positive/ binding positive $(\mathrm{K}+/ \mathrm{B}+)$ on human $\mathrm{C} 32 \mathrm{r}$ melanoma and human umbilical cord endothelial cells, as well as monocytes (10, 22). Knobless/binding negative $(\mathrm{K}-/ \mathrm{B}-)$ variants of the $\mathrm{MC}, \mathrm{SL}$, and FCR3 strains were maintained in splenectomized monkeys (MC and SL strains) or in vitro in human $0^{+}$erythrocytes (FMG). $P$. brasilianum, $P$. vivax, and $P$. knowlesi parasites were maintained in squirrel monkeys.

Cell culture. Cryopreserved $P$. falciparum ring IE were thawed as previously described (24) and grown for 24-36 h in vitro in RPMI-1640 tissue culture medium supplemented with either $10 \%$ human $\mathrm{AB}$ serum or $15 \%$ horse serum. In some experiments, IE were cultured in a serumless medium, $\mathrm{HB102}$, containing $2.5 \%$ bovine albumin. C32r human amelanotic melanoma cells (CRL 1585; American Type Culture Collection, Rockville, MD) were cultured in RPMI-1640 supplemented with $10 \%$ FCS or $5 \%$ horse serum. Melanoma cells were scraped from flask cultures and resuspended in fresh medium at $5 \times 10^{4}$ cells $/ \mathrm{ml}$ for use in cytoadherence assays. $1-\mathrm{ml}$ aliquots were placed in wells of a 24-well tissue culture plate containing 15-mm diameter glass or plastic (Thermonox; Miles Laboratories, Evanston, IL) coverslips. The cells were then cultured for $48 \mathrm{~h}$ before use in cytoadherence assays.

Isolation and purification of GP88, TSP, and other proteins. GP88 was isolated from either C32-melanoma cells or platelets. C32 melanoma cells or platelets were extracted in $1 \%$ Triton X-100 detergent. After centrifugation at $15,000 \mathrm{~g}$ for $20-30 \mathrm{~min}$, the detergent extract was passed through an affinity column of either MAb OKM5 or 8A6 covalently coupled to Affigel 10 agarose beads. The column was washed extensively and sequentially with NETT buffer $(0.15 \mathrm{M} \mathrm{NaCl}$, 5 mM EDTA, 50 mM Tris, $0.5 \%$ Triton X-100, pH 7.2), NETT +0.5 $\mathrm{M} \mathrm{NaCl}$, and PBS, $\mathrm{pH}$ 7.2. The column was eluted with $0.2 \mathrm{M}$ glycine, pH 2.5, fractions of eluate were collected in Tris to neutralize acidity of the samples and dialysed against PBS. Fractions were assayed for GP88 by RIA with ${ }^{125} \mathrm{I}$-radiolabeled OKM5 or $8 \mathrm{~A} 6$ or by PAGE and silver staining of the gel for analysis of purity.

TSP was isolated by two methods. The first method was based upon that described by Silverstein et al. (25) with modifications. Briefly, washed platelets were stimulated with calcium ionophore A23187 (2 $\mu \mathrm{M})$ in the presence of $\mathrm{Ca}^{2+}$ and protease inhibitors. The supernatant was then applied to a heparin Sepharose CL-4B affinity column, followed by elution with $0.45 \mathrm{M} \mathrm{NaCl}$ and chromatography on a mono $Q$ anion-exchange FPLC column. The applied proteins were eluted with a continuous gradient from 0 to $0.8 \mathrm{M} \mathrm{NaCl}$. TSP eluted at $0.6 \mathrm{M}$
$\mathrm{NaCl}$. The second method was a modification of Haverstick et al. (26) for production of calcium-replete TSP. Washed platelets suspended in $0.15 \mathrm{mM} \mathrm{NaCl}, 20 \mathrm{mM}$ Tris, $5 \mathrm{mM} \mathrm{CaCl}_{2}, 2 \mathrm{nM} \mathrm{MgCl}_{2}$ buffer (pH 7.2) were stimulated with alpha thrombin. The supernatant was passed over a gelatin Sepharose 4B affinity column several times. The flow through material was then applied to a heparin Sepharose 4B column. Bound TSP was eluted with $0.45 \mathrm{M} \mathrm{NaCl}, 20 \mathrm{mM}$ TRIS, $5 \mathrm{mM} \mathrm{CaCl}$, $2 \mathrm{mM} \mathrm{MgCl}$ (pH 7.2) salt solution and dialyzed against $0.15 \mathrm{M}$ $\mathrm{NaCl} / \mathrm{Ca}^{2+} / \mathrm{Mg}^{2+}$ buffered with $20 \mathrm{mM}$ Tris ( $\mathrm{pH}$ 7.2). Analysis of purity was by SDS-PAGE and silver staining.

Fibrinogen, fibronectin, vitronectin, collagen (type IV), gelatin, orosomucoid (alpha-1-acid sialoglycoprotein), glycocalicin (GP1b), histidine-rich glycoprotein (HRGP) were either purified by standard methods (27-30) or purchased from Sigma Chemical Co., St. Louis, MO.

MAbs and antisera. MAb OKM5 was a gift of Dr. Gideon Goldstein, Ortho Pharmaceuticals, Raritan, NJ, and supplied as purified antibody at $1 \mathrm{mg} / \mathrm{ml}$ in PBS. MAbs $8 \mathrm{~A} 6$ and $1 \mathrm{~B} 1$ were prepared by immunizing mice with GP88, which was partially purified by column chromatography, in Freund's complete and incomplete adjuvant and fusing the mouse spleen cells with FOX-NY myeloma cells by standard hybridoma techniques. The IgG MAbs were purified by MAPS affinity chromatography (Bio-Rad Laboratories, Richmond, CA) from mouse ascites fluid. Analysis of these MAbs, 8A6 and 1B1, was by differential RIA on purified GP88, platelets, and C32 and G361 melanoma cells compared with OKM5 (Table I). OKM5 does not react with G361 melanoma cells and these cells do not exhibit cytoadherence properties for IE $(10,11)$. Further characterization was by immunoprecipitation of GP88 from 1\% Triton X-100 detergent extracts of C32 melanoma cells biosynthetically labeled with $\left[{ }^{3} \mathrm{H}\right]$ galactosamine, $\left[{ }^{3} \mathrm{H}\right]$ mannose, and $\left[{ }^{3} \mathrm{H}\right]$ glucosamine or ${ }^{125} \mathrm{I}$-surface labeled. Both MAbs immunoprecipitated an $88-\mathrm{kD}$ band that comigrated in SDS-PAGE with the $88-\mathrm{kD}$ band of OKM5 immunoprecipitates $(10,16)$. The $50 \%$ inhibition of cytoadherence of $P$. falciparum-IE on C-32 melanoma cells for MAb OKM5 is $1 \mu \mathrm{g} \mathrm{Ab} / \mathrm{ml}$ and $0.1 \mu \mathrm{g} / \mathrm{ml}$ for MAb 8A6. MAb 1B1 does not inhibit cytoadherence of IE. Antisera to GP88 and TSP was produced in rabbits using Freund's adjuvant with purified antigen at $200 \mu \mathrm{g}$ per injection. Rabbit IgG was purified on Protein A Sepharose 4B (Pharmacia Fine Chemicals, Piscataway, NJ) affinity columns. Rabbit anti-GP88 IgG was further affinity purified on columns of GP- 88 conjugated to Affigel 15 beads.

Measurement of TSP concentration in plasma and removal of TSP from human serum. $100 \mu \mathrm{l}$ of a mouse anti-TSP MAb was coated on U-bottom 96-well polyvinylchloride RIA plates (Dynatech Laboratories, Alexandria, VA) at $20 \mu \mathrm{g} / \mathrm{ml}$. After washing and blocking with RIA grade BSA, $200 \mu$ l of test samples or known concentrations of TSP

Table I. Characterization of MAbs Reactive with 88-kD Glycoprotein (CD36)

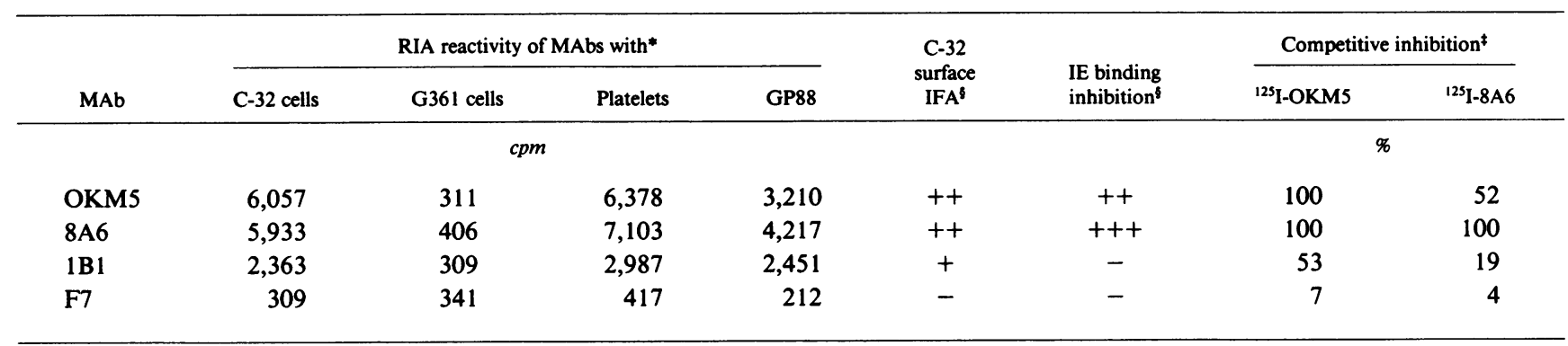

* Hybridoma supernatants or purified MAb (OKM5) were screened on polyvinyl chloride RIA plates precoated with poly-L-lysine and melanoma cells $\left(1 \times 10^{8} / \mathrm{ml}\right)$, platelets $\left(7 \times 10^{9} / \mathrm{ml}\right)$ purified, or GP88 antigen $(10 \mu \mathrm{g} / \mathrm{ml})$. G361 human melanotic melanoma cells do not bind infected erythrocytes (11) and do not react with MAb OKM5 (10) and serve as a negative control for GP88 expression. F7 is a negative control monoclonal antibody supernatant reactive with human erythrocytes. Detection of bound antibodies was with radioiodinated affinity-purified goat anti-mouse IgG. ${ }^{\ddagger 125}$ I-labeled OKM5 and $8 \mathrm{A6}$ were tested in a competitive binding inhibition assay for reactivity with purified GP88 after the bound glycoprotein was incubated with excess cold MAbs OKM5, 8A61B1, and F7 in PBS (100 $\mu \mathrm{g} / \mathrm{ml})$. ${ }^{\S}$ Supernatants were also screened on unfixed, viable $\mathrm{C} 32 \mathrm{r}$ melanoma cells and platelets by indirect immunofluorescence and for inhibition of infected erythrocyte binding. 
were added to wells. The plates were washed after $2.5 \mathrm{~h}$ and $100 \mu \mathrm{l}$ of ${ }^{125}$ I-iodogen radiolabeled rabbit anti-TSP $\mathrm{IgG}$ at $10^{5} \mathrm{cpm} /$ well was added, incubated for $2 \mathrm{~h}$ and washed and wells were counted in a gamma counter (LKB Instruments, Gaithersburg, MD). Reproducible sensitivity of this procedure with TSP standards was $\sim 2.0 \mathrm{ng} \mathrm{TSP} / \mathrm{ml}$.

TSP was removed from RPMI- 1640 medium containing $10 \%$ human serum by passing the serum several times through columns of heparin-Sepharose CL-4B (15 ml) (Sigma Chemical Co.) on two separate occasions. Samples of the medium were quantitatively analyzed for TSP content by RIA against known TSP standard curves.

Cytoadherence assays. P. falciparum trophozoite/schizont IE were washed twice and resuspended in either RPMI-1640 medium without serum and $\mathrm{Na}_{2} \mathrm{HCO}_{3}(\mathrm{pH}$ 6.9) or $\mathrm{PBS} / 0.2 \%$ glucose (pH 6.9) to a $1 \%$ PCV. $0.5 \mathrm{ml}$ of this suspension was placed in the wells of a 24-well tissue culture plate containing coverslips with $\mathrm{C} 32$ melanoma cells. Plates were rocked for $1 \mathrm{~h}$, coverslips removed and washed by gentle dipping in wash solutions, fixed in $0.5 \%$ glutaraldehyde, Giemsa stained, and the number of bound IE per 100 melanoma cells were counted.

Binding of infected erythrocytes to purified proteins was assayed on plastic bacteriological grade petri dishes (model 1007; Falcon Labware, Oxnard, CA). 20- $\mu$ l drops of purified proteins in PBS or Tris-buffered saline (TBS) (pH 7.2) were deposited in petri dishes and incubated at $37^{\circ} \mathrm{C}$ in a humidified chamber for $4 \mathrm{~h}$ to allow absorption of the proteins to the plastic surface. The excess fluid was removed, dishes washed in TBS solutions containing or lacking $\mathrm{Ca}^{2+}$, and blocked with $1 \%$ BSA for $1 \mathrm{~h}$. $1 \% \mathrm{vol} / \mathrm{vol}$ suspensions of infected erythrocytes (8-15\% parasitemia) were added to the petri dishes, rocked for $1 \mathrm{~h}$ and gently washed. The bound IE were then fixed, stained, and counted.

Localization of glycoprotein 88 (CD36) in the capillaries of human brains. The postmortem brain tissues of three Burmese with cerebral malaria infected with Plasmodium falciparum and three normal brains of accident victims autopsied at Case Western Reserve University (Cleveland, $\mathrm{OH}$ ) were fixed in $10 \%$ buffered formalin for light microscopy. After fixation, they were embedded in paraffin.

A peroxidase anti-peroxidase (PAP) method was applied to tissue sections for the purpose of examining the distributions of CD36 (GP88) in the brain vasculature. The antibodies used were MAb 8A6 anti-GP88 and affinity-purified rabbit anti-GP88 polyclonal IgG antibody. The MAb was incubated with sections overnight at $4^{\circ} \mathrm{C}$ at dilutions of 40 and $4.0 \mu \mathrm{g} / \mathrm{ml}$, and then incubated with goat anti-mouse IgG (1:20 dilution) for $30 \mathrm{~min}$. followed by mouse PAP complex (1:20 dilution) for $1 \mathrm{~h}$.

Polyclonal antibody was incubated overnight at room temperature at dilutions of 20 and $2 \mu \mathrm{g} / \mathrm{ml}$, and then incubated with goat anti-rabbit IgG (1:50 dilution) for $15 \mathrm{~min}$, following with rabbit PAP complex (1:20). After developing with 3,3'-diaminobenzidine, these sections were counterstained with Harris' hematoxylin. The routine staining techniques have been described in detail before $(31,32)$.

\section{Results}

Competitive inhibition of IE cytoadherence by purified GP88. GP88 was affinity purified on either 8A6 or OKM5-Sepharose 4B columns. Fractions eluted from the column after dialysis were analyzed by radioimmunoassay, protein content (OD 280 ), purity (SDS-PAGE/silver staining), and inhibition of cytoadherence. The fractions containing soluble purified GP88 competitively and specifically inhibited cytoadherence of IE on C32 melanoma cells (Fig. 1). The degree of inhibition mirrored proportionately the content of GP88 present in the inhibitory fractions as judged by OD 280, RIA, and SDSPAGE/silver staining. Similar concentrations of orosomucoid did not inhibit IE cytoadherence. Additionally, prior incubation of MAb OKM5 with the pooled fractions of GP88 reversed the competitive inhibition of cytoadherence, as

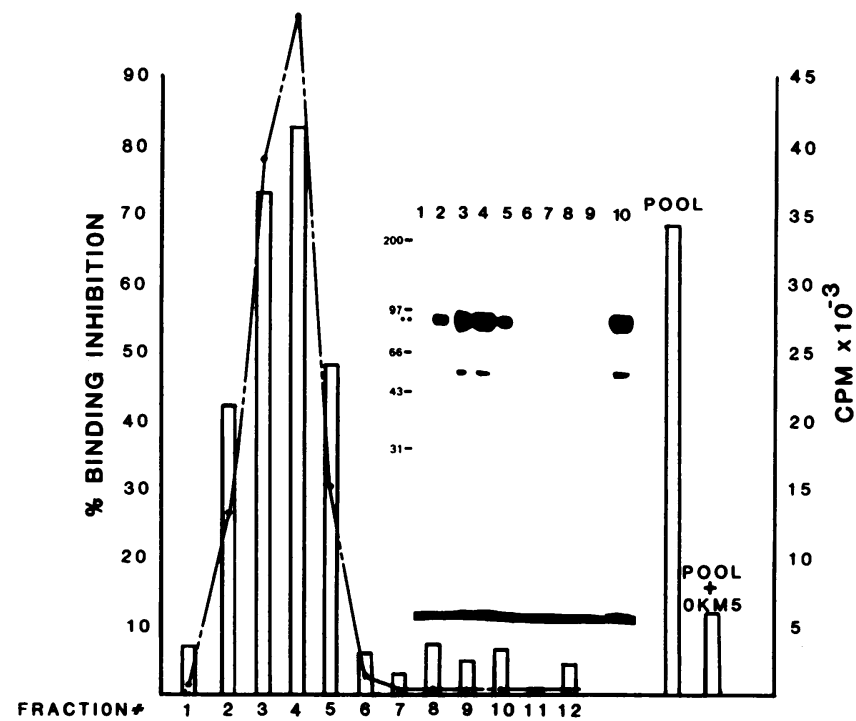

Figure 1. Analysis of fractions eluted from OkM5-Sepharose CL-4B affinity column for competitive inhibition of IE cytoadherence to C32 melanoma cells and purity of fractions; $\square$, percent inhibition of binding, $\bullet$, counts per minute of ${ }^{125}$ I-OKM5 bound to absorbed fractions. (Inset) SDS-PAGE and silver-stain analysis of eluted fractions; lanes $1-9$ correspond to fractions $1-9$. Lane 10 is a pool of fractions $2,3,4$, and $5 . \mathrm{OD}_{280}$ of positive fractions ranged between 0.08 and 0.21 .

reported before with dialysed extracts of C32 melanoma cells (10).

Cytoadherence to purified proteins. GP88 and other glycoproteins or proteins involved in cellular adhesion were coated onto plastic petri dishes at $100 \mu \mathrm{g}$ protein $/ \mathrm{ml}$ for assaying the ability to mediate cytoadherence of $P$. falciparum-infected

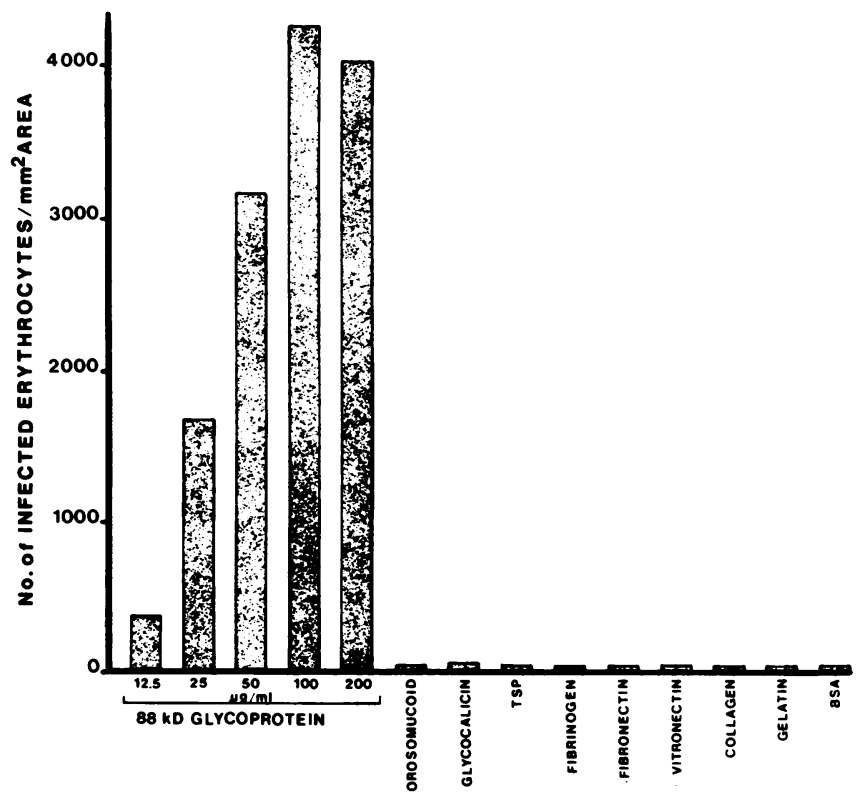

Figure 2. Cytoadherence of IE to affinity-purified GP88 and other proteins $(100 \mu \mathrm{g} / \mathrm{ml})$ bound to plastic (model 1007; Falcon Labware; petri dishes). Proteins were solubilized in PBS (pH 7.2) and dishes were washed in PBS or HBSS. Values are average of duplicates. 


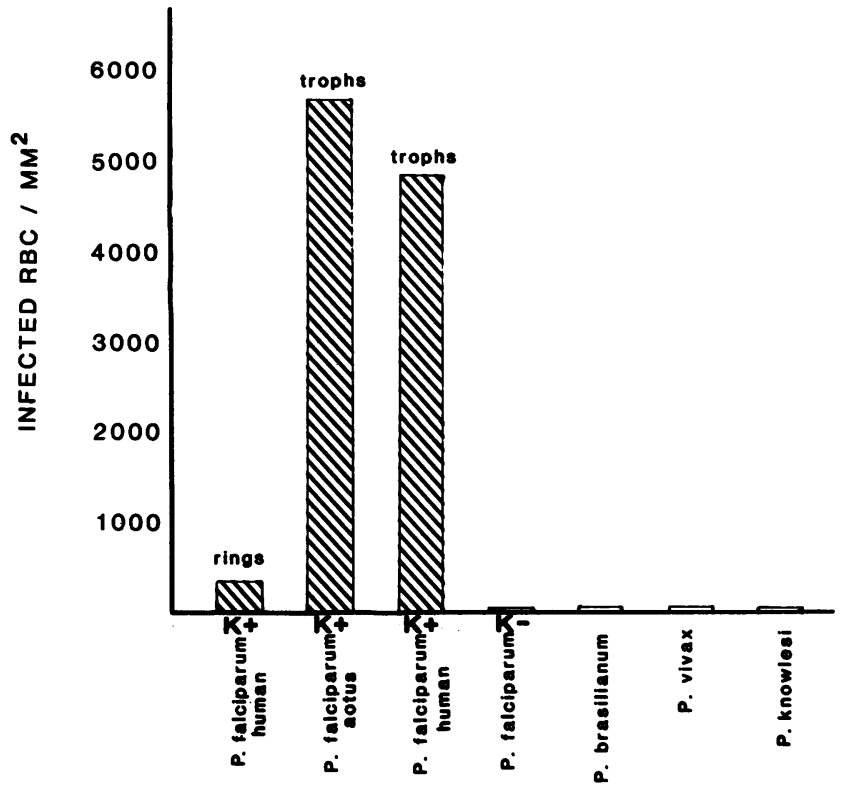

Figure 3. Cytoadherence of human, Aotus, or Saimiri erythrocytes infected with different growth stages (rings or trophozoites) and phenotypes of $P$. falciparum (FCR3) and different malaria parasite species to GP88 absorbed on plastic petri dishes. IE infected with K-P. falciparum parasites and other malarial species were predominantly at the trophozoite stage of growth. erythrocytes. $P$. falciparum infected erythrocytes specifically bound only to GP88 under the conditions the assays were conducted (Fig. 2). No IE bound to the other proteins tested, including HRGP (not shown in Fig. 2). More than 99\% of the erythrocytes bound to the area of plastic coated by GP88 were infected, although the starting parasitemia of the cell suspensions were from 6 to $12 \%$ (Fig. 3). Only the $\mathrm{K}+/ \mathrm{B}+$ phenotype of $P$. falciparum (FMG strain) trophozoite-infected erythrocytes, whether the erythrocytes were of Aotus monkey or human origin, were able to adhere to the absorbed GP88 (Fig. 4). Ring stage-infected erythrocytes of the FCR3 K+/B+ strain or trophozoite IE of the FCR 3 knob negative strain of $P$. falciparum did not adhere to GP88, just as they do not adhere to endothelial or C32 melanoma cells $(8,11,21)$. Erythrocytes infected with three other $\mathrm{K}+/ \mathrm{B}+$ strains of $P$. falciparum and two knobless counterpart strains were also tested for adherence to GP88. Adherence of the $\mathrm{K}+/ \mathrm{B}+\mathrm{MC}, \mathrm{SL}$, and FVO strains was positive with $5,160 \pm 503,5,920 \pm 472$, and $4,840 \pm 398$ IEbound $/ \mathrm{mm}^{2}$. The SL and MC knob-negative IE did not bind to GP88 (23 \pm 16 and $17 \pm 12 \mathrm{IE} / \mathrm{mm}^{2}$, respectively).

Erythrocytes infected with other malaria species that do not sequester in vivo ( $P$. vivax, $P$. knowlesi, and $P$. brasilianum) were also tested and did not attach to the immobilized GP88. Treatment of the MC strain $\mathrm{K}+/ \mathrm{B}+$ trophozoite IE with trypsin $(10 \mu \mathrm{g} / \mathrm{ml})$ or chymotrypsin $(10 \mu \mathrm{g} / \mathrm{ml})$ for $10 \mathrm{~min}$ completely abolished adherence to GP88, whereas neuramini-

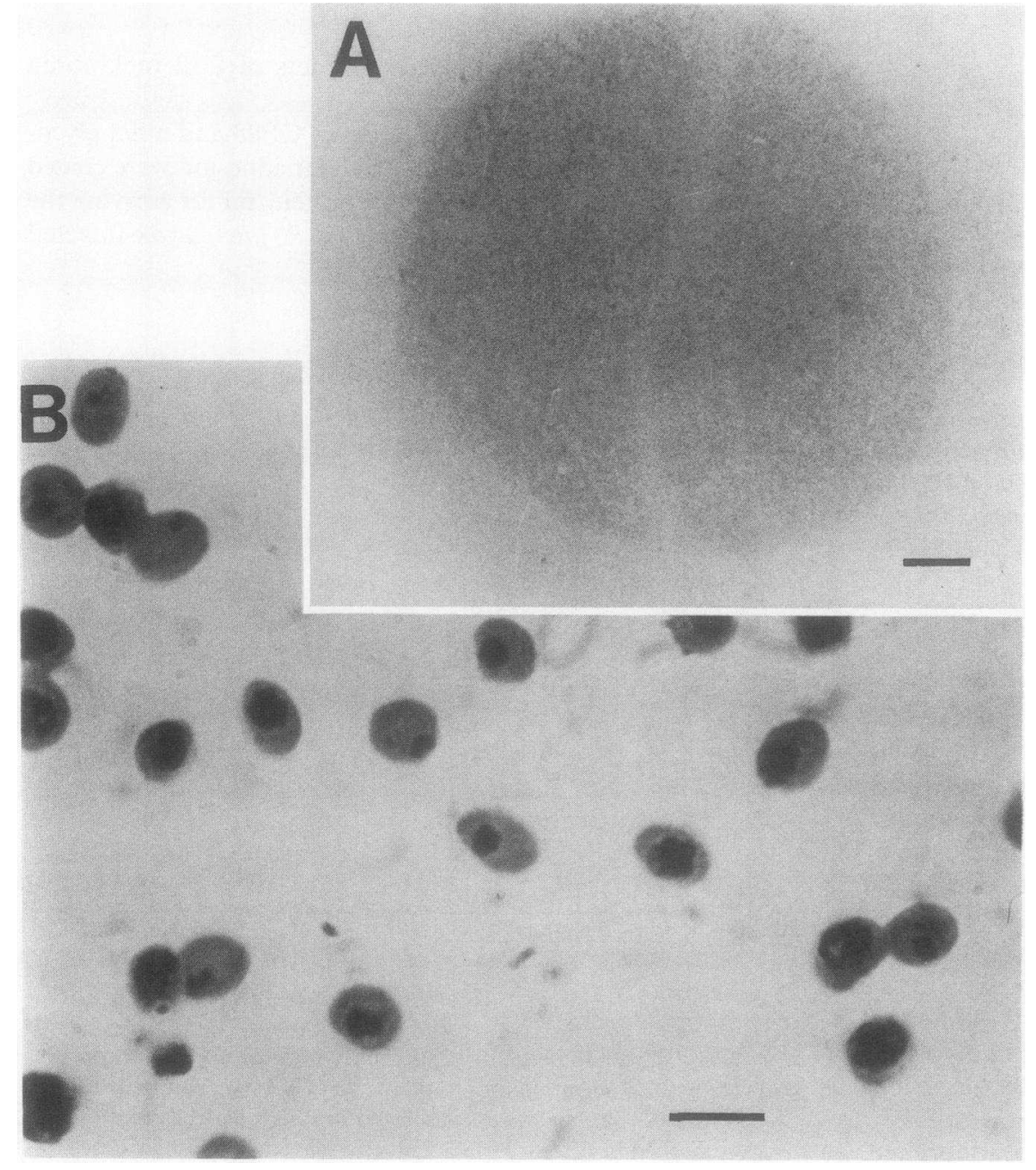

Figure 4. Photomicrographs of binding of IE to GP88 coated on to plastic surfaces. $(A)$ Granular appearance of the Giemsa-stained area of protein application after adherence of IE. (B) Oil immersion field of A showing only IE bound to GP 88 . 
Table II. Antibody Inhibition of IE Binding to C32r Melanoma Cells, GP88, and TSP

\begin{tabular}{lcccc}
\hline & & \multicolumn{3}{c}{ Infected erythrocytes bound } \\
\cline { 3 - 5 } \multicolumn{1}{c}{ Antibody } & Concentration & C32r cells & Purified GP-88 & Purified TSP \\
\hline \multirow{4}{*}{ 1B1 } & $\mu g / m l$ & \multicolumn{4}{c}{$\%$ of control } \\
OKM5 & 50 & $106 \pm 11$ & $98 \pm 9$ & \\
8A6 & 50 & 0 & $22 \pm 6$ & $89 \pm 4$ \\
& 10 & 0 & $56 \pm 10$ & \\
& 50 & 0 & $3 \pm 3$ & $96 \pm 5$ \\
Rabbit anti-GP88 & 10 & 0 & $16 \pm 5$ & \\
& 1.0 & 0 & $72 \pm 6$ & \\
Rabbit anti-TSP & 50 & 0 & 0 & $99 \pm 6$ \\
Normal rabbit & 100 & $9 \pm \pm 5$ & $19 \pm 11$ & \\
& 100 & $98 \pm 7$ & $94 \pm 9$ & $97 \pm 7$ \\
\hline
\end{tabular}

MAbs and rabbit IgG against GP88 were incubated with C32 melanoma cells and immobilized GP88 for $1 \mathrm{~h}$ before adding the IE ( $P$. falciparum/MC) suspension. Rabbit anti-TSP was added to substrates and the IE $1 \mathrm{~h}$ before performance of the cytoadherence assays. Rabbit anti-GP88 and anti-TSP were affinity-purified on GP88 and TSP-affigel 15 columns.

dase treatment $(20 \mathrm{mU} / \mathrm{ml})$ for 2 hours had no effect (data not shown). Similar results have been reported for the effect of these enzymes on cytoadherence to C32 melanoma cells $(20,33)$.

Inhibition of IE cytoadherence to GP88 and C32 melanoma cells by antibodies. Both MAbs OKM5 and 8A6, as well as rabbit anti-GP88, blocked the adherence of infected erythrocytes to $\mathrm{C} 32$ melanoma cells. All three antibody reagents also blocked the adherence of IE to immobilized GP88 (Table II). A third MAb, 1B1, which reacts with a GP88 determinant distinct from the 8A6 and OKM5 epitopes, did not block cytoadherence of IE to C32 melanoma cells or GP88. Rabbit anti-TSP did not block cytoadherence of infected erythrocytes to C-32 melanoma cells or to immobilized GP88. Rabbit antiTSP antisera did inhibit cytoadherence of IE to TSP bound to plastic, as has been reported previously (17).

Table III. Cytoadherence of IE after Removal of TSP from $P$. falciparum Growth Medium

\begin{tabular}{|c|c|c|c|c|}
\hline \multirow[b]{2}{*}{ Serum treatment } & \multirow[b]{2}{*}{$\begin{array}{l}\text { TSP in } \\
\text { medium }\end{array}$} & \multicolumn{2}{|c|}{ GP88 purified from } & \multirow{2}{*}{$\begin{array}{c}\text { C32 } \\
\text { melanoma } \\
\text { cells }\end{array}$} \\
\hline & & $\begin{array}{c}\mathrm{C} 32 \\
\text { melanoma }\end{array}$ & $\begin{array}{l}\text { Human } \\
\text { platelets }\end{array}$ & \\
\hline & $n g / m l$ & & & \\
\hline None & 4,700 & 2,460 & 2,330 & 1,780 \\
\hline Albumin-Sepharose & 3,900 & 2,840 & 2,480 & 1,670 \\
\hline Heparin-Sepharose $(\times 1)$ & 19.0 & 2,730 & 2,820 & 1,590 \\
\hline Heparin-Sepharose $(\times 2)$ & $\leqslant 2.0$ & 2,690 & 2,780 & 1,810 \\
\hline No serum (albumin) & $\leqslant 2.0$ & 2,530 & 2,460 & 1,730 \\
\hline
\end{tabular}

Values shown are IE bound per $\mathrm{mm}^{2}$ for plastic immobilized GP88 and IE per 100 target cells for C32r melanoma cells. TSP in culture medium was determined by RIA with known standards of purified TSP.
Table IV. Calcium Dependence of Binding of P. falciparum IE to C32 Melanoma Cells, Purified GP88, and Purified TSP

\begin{tabular}{llll}
\hline & \multicolumn{3}{c}{ Cytoadherence of IE with } \\
\cline { 2 - 4 } \multicolumn{1}{c}{ Cytoadherence assay treatment } & GP88 & TSP & $\begin{array}{c}\text { C32r } \\
\text { melanoma }\end{array}$ \\
\hline $\begin{array}{l}\text { PBS as blocking and washing solution } \\
\text { (pH 7.2) }\end{array}$ & 3,970 & $<50$ & 1,380 \\
$\begin{array}{l}\text { TBS/Ca }{ }^{2+} \text { as blocking and washing } \\
\text { solution (pH 7.2) }\end{array}$ & 4,260 & 4,610 & 1,280 \\
$\begin{array}{l}\text { TBS as blocking and washing solution } \\
\text { (pH 7.2) }\end{array}$ & 4,140 & 2,190 & 1,190 \\
$\begin{array}{l}\text { TBS + 10 mm EDTA as blocking and } \\
\text { washing solution }\end{array}$ & 4,380 & $<50$ & 1,340 \\
$\begin{array}{l}\text { Serumless medium, TBS/Ca } \\
\text { and washing solution }\end{array}$ & 3,790 & 4,120 & 1,090 \\
\hline
\end{tabular}

Values shown are number of infected erythrocytes bound per $\mathbf{~ m m}^{2}$ in the case of immobilized GP88 and TSP and number of IE attached per 100 cells in the case of C32r melanoma cells.

Requirement of TSP for mediating cytoadherence of IE to GP88 or C32 melanoma cells. Inasmuch as IE bind to TSP (17) and TSP interacts with GP88 (18) the role of TSP mediating either GP88/IE or C-32 melanoma/IE interactions was investigated. First, IE were grown from ring stage to trophozoite-stage parasites in either medium with serum depleted of TSP or in serumless medium. These IE bound to either GP88 or C32 melanoma cells in quantities equal to that of infected cells grown in medium supplemented with untreated serum (Table III). Secondly, investigation of the $\mathrm{Ca}^{2+}$ dependence of cytoadherence revealed that cytoadherence of IE to C32 melanoma cells or GP88 was $\mathrm{Ca}^{2+}$ independent, whereas IE binding to TSP is strictly $\mathrm{Ca}^{2+}$ dependent. Binding assays done in either $10 \mathrm{mM}$ EDTA or PBS show that the IE will bind to GP88 and C-32 melanoma cells whereas IE binding to calcium-replete TSP is abolished (Table IV). IE do not bind to noncalcium-replete TSP (Fig. 2).

Localization of GP88 on brain endothelium. Postmortem human brain sections from accident victims or from patients succumbing to cerebral malaria were incubated with $\mathrm{MAb}$ 8A6, rabbit anti-GP88 IgG affinity purified on GP88 conjugated to Affigel 15 normal mouse IgG, or normal rabbit IgG. The sections, developed with either goat anti-rabbit or antimouse HRP conjugate, showed GP88 to be present on endothelial cells of brain tissue vessels in both normal accident and cerebral malaria victims (Fig. 5). The less intense reactions in cerebral malaria specimens is most probably artifactual because these sections were in storage for a longer time period and were subjected to harsher fixation conditions.

\section{Discussion}

The determination of the molecular moieties involved in the adhesive interaction of $P$. falciparum IE and vascular endothelium is an essential step for understanding the biological consequences of sequestration. Previously, it was shown that an MAb (OkM5), recognizing an 88-kD glycoprotein on human cells that specifically bind $P$. falciparum IE, would inhibit and reverse cytoadherence (10). It was also demonstrated by Roberts et al. that IE could specifically adhere to TSP (17), an adhesive glycoprotein synthesized by numerous cell types and involved in cell-cell and cell-matrix interactions (16). We and 

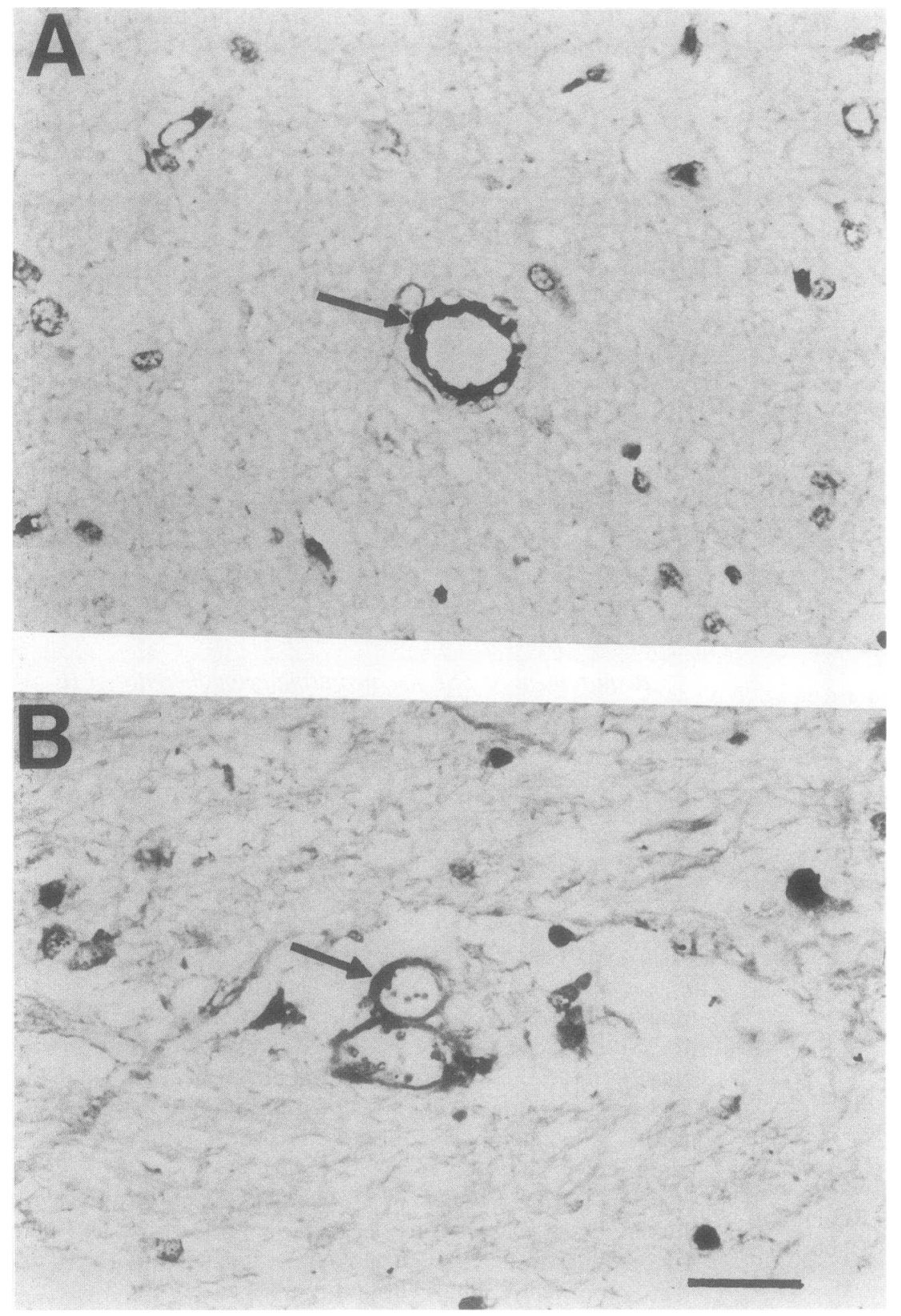

Figure 5. Immunoperoxidase reaction of MAb $8 \mathrm{~A} 6$ with sections of fixed brain tissue from nonmalarial individual $(A)$ and from a cerebral malaria patient $(B)$. Thick arrows show area of staining on vessel endothelium and thin arrow shows IE of infected patient. others have subsequently presented data that GP88 (CD36) is probably the same as platelet glycoprotein $(16,34)$ and binds TSP either in a purified or cell bound state in a $\mathrm{Ca}^{2+}$-dependent fashion (18). These results suggested that cytoadherence of IE could involve three elements, GP88 (CD36), TSP, and a parasite-induced ligand on the infected erythrocyte surface (Fig. 6).

TSP is synthesized by endothelial cells (35), monocytes (36), and C32 melanoma cells and is found in serum (20-50 $\mu \mathrm{g} / \mathrm{ml})$ and plasma $(100 \mathrm{ng} / \mathrm{ml})$. Thus this multifunctional protein could be a central mediating element of cytoadherence either by first attaching to the surface of tissue cells via GP88 (CD36), or to the surface of IE via parasite-binding ligand. A third alternative would be that infected erythrocytes can bind directly to GP88 (GPIV) independent of TSP. The results of this study indicate that the latter hypothesis is most likely correct.
First, to show that previous inhibition of binding by $\mathrm{C} 32$ melanoma cell extracts was specifically due to GP88 (10), we affinity purified this glycoprotein and used it to competitively inhibit IE cytoadherence to C32 melanoma cells (Fig. 1). This indicated that GP88 (purified either from C32 melanoma cells or platelets) was capable of interfering with cytoadherence of IE and suggested a receptor-like role in this interaction. Further, additional evidence of this receptor role for GP88 was obtained by demonstrating that only IE that exhibit cellular cytoadherence properties IE bind specifically and directly to immobilized GP88. This binding of IE to immobilized GP-88 or C32 melanoma cells can be prevented by MAbs OKM5 and $8 \mathrm{~A} 6$ or mouse or rabbit anti-GP88 IgG but not by several rabbit antisera to TSP, although anti-TSP blocks IE binding to TSP (17). This result suggested but did not rule out the possibility that TSP was not involved as an intermediary in the adherence of IE to GP88. 


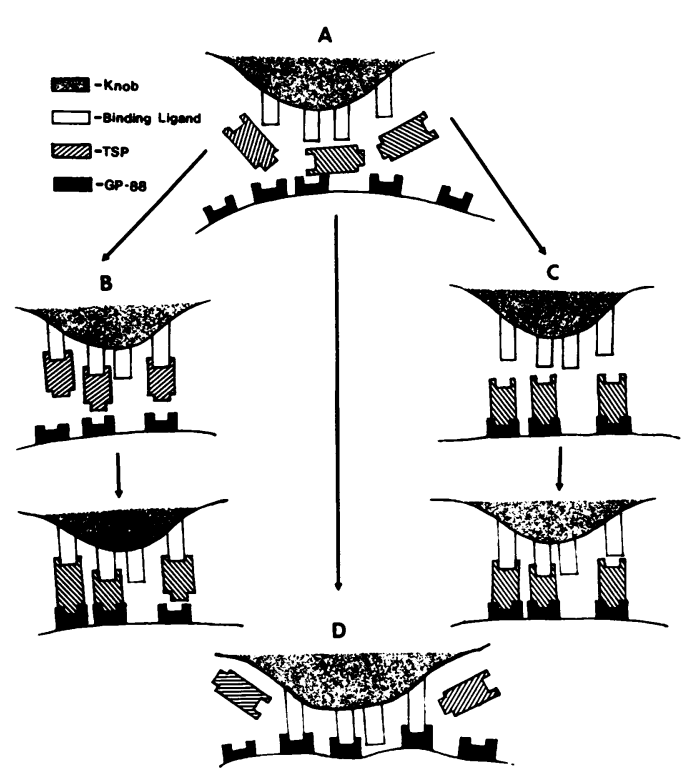

Figure 6. Schematic representation of molecular elements postulated to be involved in cytoadherence and sequestration of $P$. falciparum IE and the possible interactive pathways. $(A)$ Molecular elements suspected of being involved in sequestration and in vitro cytoadherence of IE; $(B)$ soluble TSP in plasma associates with exposed parasite-induced ligand expressed predominantly over the electron-dense knob protrusions of the membrane of infected erythrocytes. The TSP-ligand complex then interacts with $88-\mathrm{kD}$ glycoprotein (CD36) on melanoma or endothelial cells; $(C)$ plasma or cellular synthesized TSP associated with surface membrane receptor interacts with circulating infected glycoprotein erythrocytes expressing cytoadherence ligand; and $(D)$ knob-associated, parasite-induced cytoadherence ligand interacts with cell membrane bound glycoprotein receptor independent of mediation by TSP.

TSP binding to GP88 and IE is strictly $\mathrm{Ca}^{2+}$ dependent (Table III, 18). Removal of $\mathrm{Ca}^{2+}$ from TSP causes an unfolding of its tertiary globular structure and inhibits interaction with other adhesive proteins (reviewed in reference 16). Binding of IE to GP88 or C32 melanoma cells occurs equally well in isotonic solutions with or without $\mathrm{Ca}^{2+}$ as well as in the presence of EDTA (Table III). This again indicated that TSP probably is not involved in the adherence of IE to either purified GP88 or C32 melanoma cells. Further evidence for this was obtained by either culturing parasites in medium containing serum, medium with serum depleted of TSP, or in serumless tissue culture medium and comparing the binding of IE to GP88 and C32 melanoma cells. Binding was comparable in all cases. Thus, it would appear that GP88 is a cell receptor for the cytoadherence of IE and interacts directly with a ligand on the IE surface independent of TSP.

Because IE attach to both GP88 and TSP but under differing conditions one could speculate on the existence of two different ligands on the surface of IE or a single ligand with differing functional domains. One high-molecular weight parasite encoded protein exposed on the surface of IE has been identified and has been proposed as a candidate ligand involved in cytoadherence $(20,37,38)$. The evidence for this is indirect and to date, specific immunological reagents have not been produced to enable further evaluation of this proposal. Recently, the gene encoding a blood-stage $P$. falciparum protein (TRAP) was reported to contain regions of sequence homology to TSP. The authors raised the speculation that this protein may mediate cytoadherence of IE to GP88 or TSP analogous to TSP binding to GP88 $(39,40)$. However, it was not demonstrated that TRAP was present on the surface of IE. Preliminary results using peptides to these regions of homology, CSVTCG, WSPCSVTCG, and RGDS in cytoadherence inhibition assays suggest these domains are not involved in cytoadherence of IE to C32 melanoma cells or immobilized GP88. At $1 \mathrm{mM}$ concentrations, these peptides did not inhibit cytoadherence (Barnwell J., unpublished observation), whereas the CSVTCG peptide does inhibit the interaction of GP88 and HRGP with TSP (Nachman, R., and A. Asch, unpublished observations). The demonstration that GP88 interacts directly with IE in the absence of demonstrable TSP mediation and the production of monoclonal antibodies which inhibit cytoadherence may now offer new approaches for conclusively identifying the elusive cytoadherence ligand of $P$. falciparum infected erythrocytes. The isolation of the corresponding gene and its product would add one more important component to the development of a vaccine against malignant tertian malaria.

IE sequestration has also been hypothesized to be related to the development of cerebral malaria syndrome, which occurs in a small proportion of falciparum malaria cases (5-7). Because $P$. falciparum IE adhere directly to GP88 and this glycoprotein is known to be present on vascular endothelium in some tissue sites and not in others (41), we investigated the expression of GP88 in brain endothelium. The increased expression of OKM5 antigen (CD36) is inducible in a monocytic cell line (15) and is absent from some endothelium, such as kidney tissue (41). The induced expression of the CD36 molecule by brain endothelial cells during a falciparum malaria infection with subsequent sequestration of IE in this site could in part explain the genesis of the cerebral malaria syndrome. However, we find that CD36 (GP88) is constitutively expressed on endothelial cells in both normal and cerebral malaria brain tissue. This would suggest that IE sequestration and endothelial adhesiveness per se probably are not directly causal in the induction of the onset of cerebral malaria and other associated factors (42) need to be investigated more closely in human malaria cases.

\section{Acknowledgments}

We wish to thank Mrs. Bea Robles for typing and editing this manuscript.

This work was supported by a National Institutes of Health grant 2PO1 HL-21016-11.

\section{References}

1. Bignami, A., and G. Bastianelli. 1889. Observations of EstivoAutumnal malaria. Reforma Medica. 6:1334-1335.

2. Luse, S. A., and L. H. Miller. 1971. Plasmodium falciparum malaria. Ultrastructure of parasitized erythrocytes in cardiac vessels. Am. J. Trop. Med. Hyg. 20:655-660.

3. Howard, R. H., and J. W. Barnwell. 1984. Role of surface antigens on malaria-infected red blood cells in evasion of immunity. In Contemporary Topics in Immunobiology. Vol. 12. Immunobiology of Parasites and Parasitic Infections. J. J. Marchalonis, editor. Plenum Press, New York. 127-191.

4. Wyler, D. J., C. N. Oster, and T. C. Quinn. 1979. The role of the spleen in malaria infections. In The Role of the Spleen in Immunology of Parasitic Diseases. Tropical Disease Research Series No. 1. Schwabe \& Co., Basel, Switzerland. 183-204.

5. Aikawa, M., M. Suzuki, and Y. Gutierrez. 1980. Immunopathology of malaria. In Malaria: Immunology, Immunopathology, and Immunization. J. P. Kreier, editor. Academic Press, New York. 47-102. 
6. MacPherson, G. G., M. J. Warrel, N. J. White, S. Looareesuwan, and D. A. Warrel. 1985. Human cerebral malaria: a quantitative ultrastructural analysis of parasitized erythrocyte sequestration. Am. J. Pathol. 119:385-394.

7. Raventos-Suarez, C., D. K. Kaul, F. Macaluso, and R. L. Nagel. 1985. Membrane knobs are required for the microcirculatory obstruction induced by Plasmodium falciparum infected erythrocytes. Proc. Natl. Acad. Sci. USA. 82:3829-3833.

8. Udeinya, I. J., J. A. Schmidt, M. Aikawa, L. H. Miller, and I. Green. 1981. Falciparum malaria infected erythrocytes specifically bind to cultured human endothelial cells. Science (Wash. DC). 213:555-557.

9. Ockenhouse, C., S. Schulman, and H. L. Shear. 1984. Induction of crisis forms in the human malaria parasite Plasmodium falciparum by $\gamma$-interferon-activated, monocyte derived macrophages. $J$. Immunol. 133:1602-1604.

10. Barnwell, J. W., C. F. Ockenhouse, and D. M. Knowles. 1985. Monoclonal antibody OKM5 inhibits In vitro binding of Plasmodium falciparum-infected erythrocytes to monocytes, endothelial, and C32 melanoma cells. J. Immunol. 135:3494-3497.

11. Schmidt, J. A., I. J. Udeinya, J. H. Leech, R. J. Hay, M. Aikawa, J. W. Barnwell, I. Green, and L. H. Miller. 1982. Plasmodium falciparum malaria: an amelanotic melanoma cell line bears receptors for the knob ligand on infected erythrocytes. J. Clin. Invest. 70:379386.

12. Panton, L. J., J. H. Leech, L. H. Miller, and R. J. Howard. 1987. Cytoadherence of Plasmodium falciparum-infected erythrocytes to human melanoma cell lines correlates with surface OKM5 antigen. Infect. Immun. 55:2754-2758.

13. Trager, W., M. A. Rudzinska, and P. C. Bradbury. 1966. The fine structure of Plasmodium falciparum and its host erythrocytes in natural malaria infections in man. Bull. WHO. 35:883-889.

14. Aikawa, M., J. R. Rabbage, and B. T. Wellde. 1972. Junctional apparatus in erythrocytes infected with malarial parasites. Z. Zellforsch. Mikrosk. Anat. 124:722-727.

15. Talle, M. A., E. Rao, N. Westburg, M. Allegar, M. Makowski, R. S. Mittler, and G. Goldstein. 1983. Patterns of antigenic expression on human monocytes as defined by monoclonal antibodies. Cell. Immunol. 78:83-92.

16. Lawler, J. 1986. The structural and functional properties of thrombospondin. Blood. 67:1197-1209.

17. Roberts, D. D., J. A. Sherwood, S. L. Spitalnik, L. J. Patton, R. J. Howard, V. M. Dixit, W. A. Frazier, L. H. Miller, and V. Ginsburg. 1985. Thrombospondin binds falciparum malaria parasitized erythrocytes and may mediate cytoadherence. Nature (Lond.). 318:64-66.

18. Asch, A., J. W. Barnwell, R. Silverstein, and R. L. Nachman. 1987. Isolation of thrombospondin membrane receptor. J. Clin. Invest. 79:1054-1061.

19. Udeinya, I. J., P. M. Graves, E. Carter, M. Aikawa, and L. H. Miller. 1983. Plasmodium falciparum: effect of time in continuous culture on binding to human endothelial cells and amelanotic melanoma cells. Exp. Parasitol. 56:207-214.

20. Leech, J. H., J. W. Barnwell, L. H. Miller, and R. J. Howard. 1984. Identification of a strain specific malarial antigen exposed on the surface of Plasmodium falciparum-infected erythrocytes. J. Exp. Med. 159:1567-1572.

21. Barnwell, J. W., R. J. Howard, and L. H. Miller. 1983. Influence of the spleen on the expression of surface antigens on parasitized erythrocytes. Ciba Found. Symp. 94:117-132.

22. Siddiqui, W. A., J. V. Schnell, and S. Richmond-Crum. 1974. In vitro cultivation of Plasmodium falciparum at high parasitemia. Am. J. Trop. Med. Hyg. 23:1015-1018.

23. Meryman, H. T., and M. Hornblower. 1972. A method for freezing and washing red blood cells using a high glycerol concentration. Transfusion (Phila.). 12:145-156.

24. Barnwell, J. W., R. J. Howard, H. G. Coon, and L. H. Miller. 1983. Splenic requirement for antigenic variation and expression of the variant antigen on the erythrocyte membrane in cloned Plasmodium knowlesi malaria. Infect. Immun. 40:985-994.

25. Silverstein, R. L., L. L. K. Leung, P. C. Harpel, and R. L. Nachman. 1985. Platelet thrombospondin forms a trimulecular complex with plasminogen and histidine-rich glycoprotein. J. Clin. Invest. 75:2065-2073.

26. Haverstick, D. M., V. M. Dixit, G. A. Grant, W. A. Frazier, and S. A. Santoro. 1984. Localization of the hemagglutinating activity of platelet thrombospondin to a 140,000 dalton thermolytic fragment. Biochemistry. 23:5597-5603.

27. Leung, L. L. K., R. L. Nachman, and P. C. Harpel. 1984. Complex formation of platelet thrombospondin with histidine-rich glycoprotein. J. Clin. Invest. 73:5-12.

28. Clemetson, K. J., H. Y. Naim, and E. F. Lüscher. 1981. Relationship between glycocalicin and glycoprotein Ib of human platelets. Proc. Natl. Acad. Sci. USA. 78:2712-2716.

29. Leung, L. L. K., and R. L. Nachman. 1982. Complex formation of platelet thrombospondin with fibrinogen. J. Clin. Invest. 70:542549.

30. Lahau, J., M. A. Schwartz, and R. O. Hynes. 1982. Analysis of platelet adhesion with a radioactive chemical cross-linking reagent: interaction of thrombospondin with fibronectin and collagen. Cell. $31: 253-262$

31. Oo, M. M., M. Aikawa, T. Than, T. M. Aye, P. T. Myint, I. Igarashi, and W. C. Schoene. 1987. Human cerebral malaria: a pathological study. J. Neuropathol. Exp. Neurol. 46:223-231.

32. Igarashi, I., M. M. Oo, H. Stanley, R. Reese, and M. Aikawa. 1987. Knob antigen desposition in cerebral malaria. Am. J. Trop. Med. Hyg. 37:511-515.

33. David, P. H., M. Hommel, L. H. Miller, I. J. Udeinya, and L. D. Oligino. 1983. Parasite sequestration in Plasmodium falciparum malaria: spleen and antibody modulation of cytoadherence of infected erythrocytes. Proc. Natl. Acad. Sci. USA. 80:5075-5079.

34. Tandon, N. N., A. Hines, and G. Jamieson. 1985. Role for platelet glycoprotein IV in collagen-induced platelet aggregation. Blood. 66:316. (Abstr.)

35. Mosher, D. F., M. J. Doyle, and E. A. Jaffe. 1982. Synthesis and secretionof thrombospondin by cultured human endothelial cells. $J$. Cell Biol. 93:343-348.

36. Jaffe, E. A., J. T. Ruggiero, and D. J. Falcone. 1985. Monocytes and macrophages synthesize and secrete thrombospondin. Blood. 65:79-84.

37. Howard, R. J., J. W. Barnwell, E. P. Rock, J. Neequaye, D. Ofori-Adjei, W. L. Maloy, J. A. Lyon, and A. Saul. 1988. Two approximately $\mathbf{3 0 0}$ kilodalton Plasmodium falciparum proteins at the surface membrane of infected erythrocytes. Mol. Biochem. Parasitol. 27:207223.

38. Magowan, C., W. Wollish, L. Anderson, and J. Leech. 1988. Cytoadherence by Plasmodium falciparum-infected erythrocytes is correlated with the expression of a family of variable proteins on infected erythrocytes. J. Exp. Med. 168:1307-1320.

39. Robson, K. J. H., J. R. S. Hall, M. W. Jennings, T. J. R. Harris, K. Marsh, C. I. Newbold, V. E. Tate, and D. J. Weatherall. 1988. A highly conserved amino-acid sequence in thrombospondin, properdin, and in proteins from sporozoites and blood stages of a human malaria parasite. Nature (Lond.). 335:79-82.

40. Lawler, J. and R. O. Hynes. 1986. The structure of human thrombospondin, an adhesive glycoprotein with multiple calciumbinding sites and homolgies with several different proteins. J. Cell Biol. 103:1635-1648.

41. Knowles, D. M., B. Tolidjian, C. Marboe, V. D'Agati, M. Grimes, and L. Chess. 1984. Monoclonal anti-human monocyte antibodies OKM1 and OKM5 possess distinctive tissue distributions including differential reactivity with vascular endothelium. J. Immunol. 132:2170-2173.

42. Grau, G. E., L. F. Fajardo, P. F. Piquet, B. Allet, P. H. Lambert, and P. Vasalll. 1987. Tumor necroais fuctor (cachectin) as an cesential mediator in murine cerebral malaria. Science (Wash. DC). 237:12101212. 